\title{
Miniature-probe endoscopic ultrasonography using a rubber balloon to evaluate gastrointestinal carcinomas in poor underwater conditions
}

Miniature-probe endoscopic ultrasonography (m-EUS) is routinely used to diagnose the invasion depth of gastrointestinal carcinomas $[1,2]$. However, the efficacy of EUS is sometimes limited in locations such as the esophagus and esophagogastric junction, where water does not accumulate sustainably $[3,4]$. A rubber balloon (MAJ-213; Olympus, Tokyo, Japan) is clinically available for attaching to a convex-type EUS probe [5]. We describe a novel m-EUS method using this rubber balloon without the need for intraluminal underwater conditions ( $\vee$ Fig. 1 ; $\triangleright$ Video 1 ).

A 74-year-old man presented with a 25-mm protruding carcinoma located at the esophagogastric junction ( $\mathbf{F i g . 2}$ ). EUS with a high-frequency 20-MHz miniature probe (UM-3R; Olympus) was performed to diagnose the tumor invasion depth. However, conventional m-EUS could not capture an underwater image because the water passed easily into the stomach. It was for this reason that we developed and used our m-EUS system, as follows. First, the rubber balloon was attached to a conventional endoscope (GIF-H260Z; Olympus) and fixed with tape. The endoscope reached the target lesion and provided an acceptable endoscopic view (> Fig.3). Now the balloon was filled with water using the water jet function and the miniature probe inserted within the water-filled balloon. m-EUS revealed a well-demarcated hypoechoic mass within the second layer and an intact submucosal layer ( $\mathbf{F i g . 4}$ ), and diagnosed the tumor depth as within the mucosa. In accordance with the EUS diagnosis, endoscopic submucosal dissection was completed. Histological examination confirmed curative resection of adenocarcinoma with mucosal invasion.

This method was also useful in another patient for diagnosing the invasion depth of a signet ring cell carcinoma located in the antrum of the remnant stomach
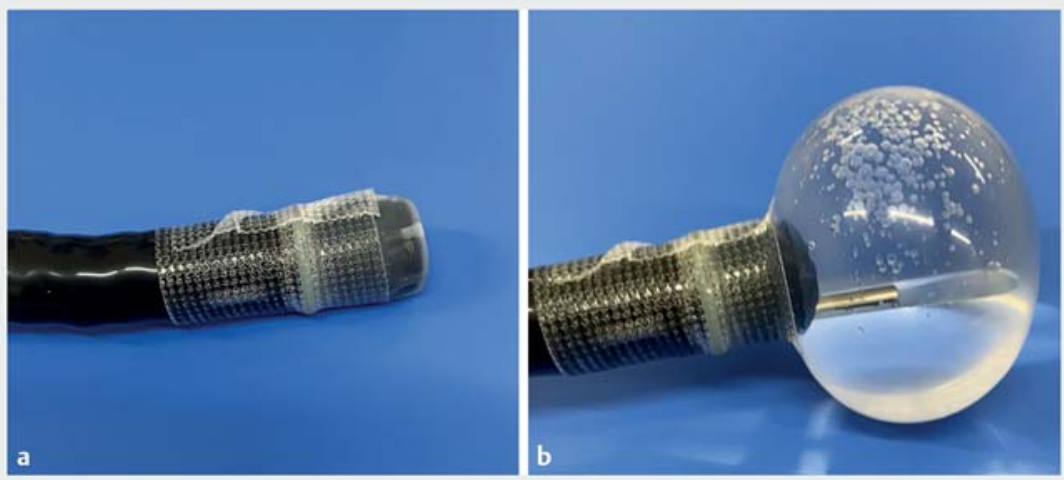

- Fig. 1 a To overcome problems of miniature-probe endoscopic ultrasonography (m-EUS) in locations such as the esophagus and esophagogastric junction, where water does not accumulate sustainably, a rubber balloon was attached to a conventional endoscope and fixed with tape. $\mathbf{b}$ The balloon was filled with water using the water jet function, and the miniature probe was inserted within the water-filled balloon.
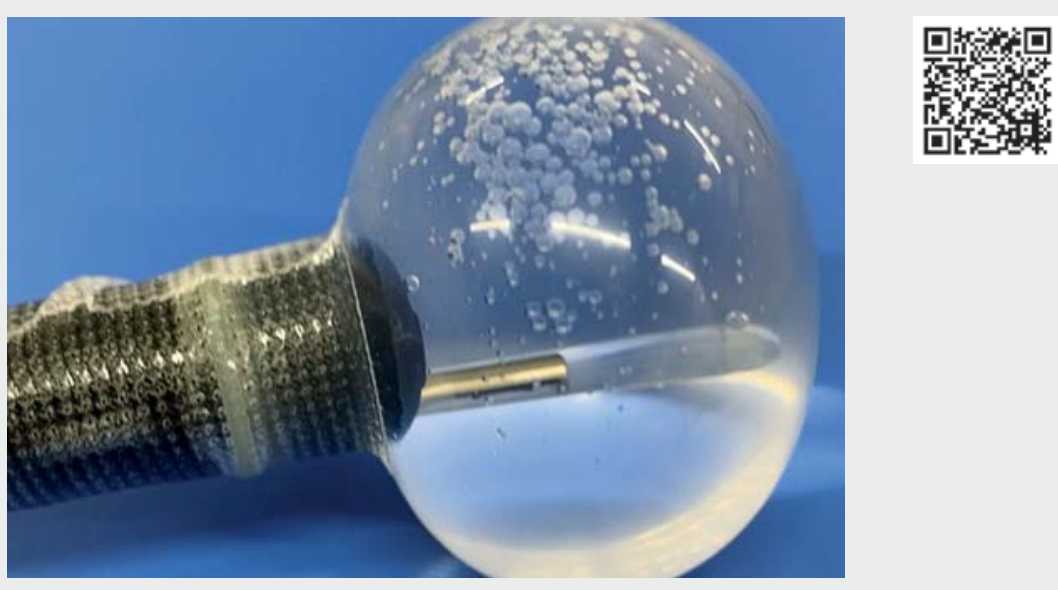

Video 1 Miniature-probe endoscopic ultrasonography using a rubber balloon to diagnose the invasion depth of a carcinoma located at the esophagogastric junction, where water pooling was poor.

where there was poor water pooling ( Fig. 5)

$\mathrm{m}$-EUS using a rubber balloon is simple and effective for resolving poor underwater visual conditions.

Endoscopy_UCTN_Code_TTT_1AS_2AG

\section{Competing interests}

The authors declare that they have no conflict of interest. 


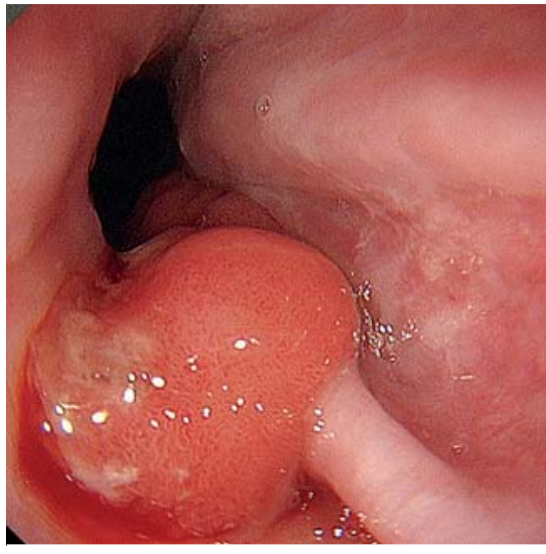

- Fig. 2 A 25-mm diameter protruding carcinoma located at the esophagogastric junction in a 74-year-old man.

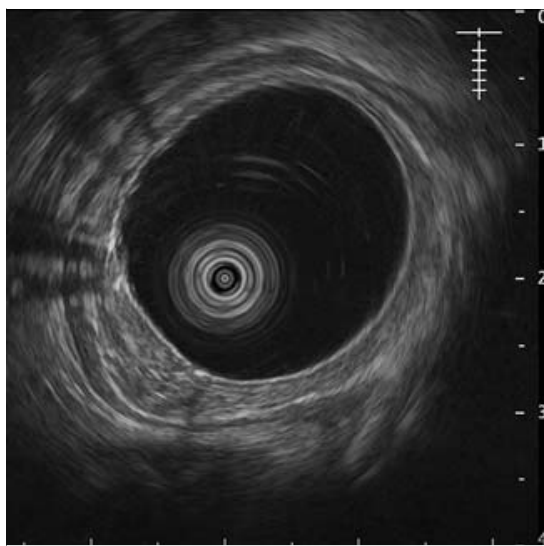

- Fig. 4 The m-EUS image showed a welldemarcated hypoechoic mass within the second layer and an intact submucosal layer.

The authors

Nobuya Kobayashi @ Hideki Kobara

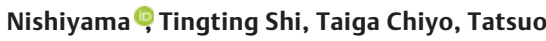
Yachida, Tsutomu Masaki

Department of Gastroenterology and Neurology, Faculty of Medicine, Kagawa University, Kita, Kagawa, Japan

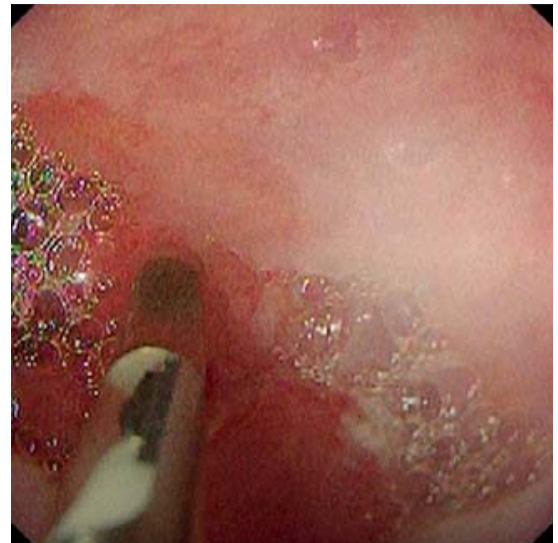

- Fig. 3 Acceptable endoscopic image under the balloon attached to the endoscope.

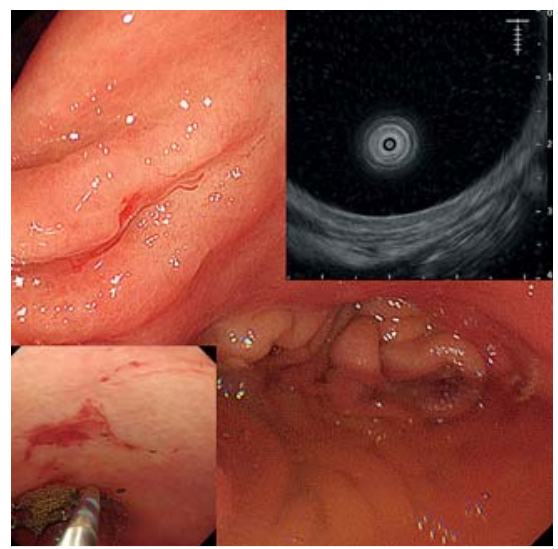

- Fig. 5 Signet ring cell carcinoma located in the antrum of the remnant stomach in another patient. The m-EUS image using the balloon also clearly visualized a hypoechoic mass within the mucosal layer.

Corresponding author

\section{Nobuya Kobayashi, MD, PhD}

Department of Gastroenterology and Neurology, Kagawa University, 1750-1 Ikenobe, Miki, Kita, Kagawa 761-0793, Japan kobayashi.nobuya.jn@kagawa-u.ac.jp

\section{References}

[1] Yang X, Wang H, Dong Q et al. An artificial intelligence system for distinguishing between gastrointestinal stromal tumors and leiomyomas using endoscopic ultrasonography (with video). Endoscopy 2021. doi:10.1055/a-1476-8931

[2] Yoshinaga S, Oda I, Nonaka S et al. Endoscopic ultrasound using ultrasound probes for the diagnosis of early esophageal and gastric cancers. World J Gastrointest Endosc 2012; 4: 218-226

[3] Hatta W, Uno K, Koike T et al. Feasibility of optical coherence tomography for the evaluation of Barrett's mucosa buried underneath esophageal squamous epithelium. Dig Endosc 2016; 28: 427-433

[4] Akashi K, Yanai H, Nishikawa J et al. Ulcerous change decreases the accuracy of endoscopic ultrasonography diagnosis for the invasive depth of early gastric cancer. Int J Gastrointest Cancer 2006; 37: 133-138

[5] Ginès A, Lightdale C]. How I do a diagnostic EUS. Endoscopy 2019; 51: 973-975

\section{Bibliography}

Endoscopy 2022; 54: E466-E467

DOI 10.1055/a-1625-3639

ISSN 0013-726X

published online 27.9.2021

(C) 2021. Thieme. All rights reserved.

Georg Thieme Verlag KG, Rüdigerstraße 14,

70469 Stuttgart, Germany

\section{ENDOSCOPY E-VIDEOS}

https:|/eref.thieme.de/e-videos

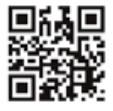

Endoscopy E-Videos is an open access online section, reporting on interesting cases and new techniques in gastroenterological endoscopy. All papers include a high quality video and all contributions are freely accessible online. Processing charges apply (currently EUR 375), discounts and wavers acc. to HINARI are available.

This section has its own submission website at

https://mc.manuscriptcentral.com/e-videos 